\title{
One Size Doesn't Fit All: Using Factor Analysis to Gather Validity Evidence When Using Art Reception Survey - Revised (Ars-Revised) On Sarawak Iban Pua Kumbu
}

Wan Juliana Emeih Wahed, Saiful Bahari Hj. Mohd Yusoff, Noorhayati Saad, Patricia Pawa Pitil

To Link this Article: http://dx.doi.org/10.6007/IJARBSS/v11-i14/8569

DOI:10.6007/IJARBSS/v11-i14/8569

Received: 30 November 2020, Revised: 27 December 2020, Accepted: 13 January 2021

Published Online: 29 January 2021

In-Text Citation: (Wahed et al., 2021)

To Cite this Article: Wahed, W. J. E., Yusoff, S. B. H., Saad, N., \& Pitil, P. P. (2021). One Size Doesn't Fit All: Using Factor Analysis to Gather Validity Evidence When Using Art Reception Survey - Revised (Ars-Revised) On Sarawak Iban Pua Kumbu. International Journal of Academic Research in Busines and Social Sciences. 11(14), 222-232.

\section{Copyright: (C) 2021 The Author(s)}

Published by Human Resource Management Academic Research Society (www.hrmars.com)

This article is published under the Creative Commons Attribution (CC BY 4.0) license. Anyone may reproduce, distribute, translate and create derivative works of this article (for both commercial and non-commercial purposes), subject to full attribution to the original publication and authors. The full terms of this license may be seen

at: http://creativecommons.org/licences/by/4.0/legalcode

Special Issue: Contemporary Business and Humanities Landscape Towards Sustainability, 2021, Pg. 222 - 232 


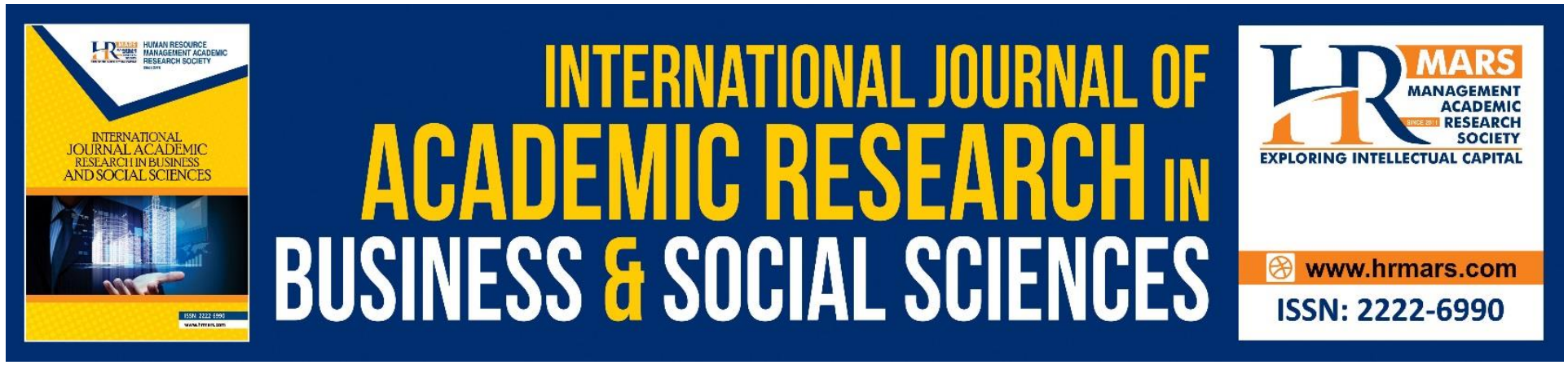

\title{
One Size Doesn't Fit All: Using Factor Analysis to Gather Validity Evidence When Using Art Reception Survey - Revised (Ars-Revised) On Sarawak Iban Pua Kumbu
}

\author{
Wan Juliana Emeih Wahed, Saiful Bahari Hj. Mohd Yusoff \\ Institute of Creative Arts and Technology (iCreaTe), Universiti Malaysia Sarawak, 94300, Kota \\ Samarahan, Sarawak, Malaysia, Faculty of Art and Design, Universiti Teknologi MARA, Cawangan \\ Sarawak, 94300, Kota Samarahan, Sarawak, Malaysia \\ Email: juliewahed@gmail.com, mysaiful@unimas.my
}

Noorhayati Saad

The Design School, Faculty of Innovation \& Technology Taylor's University, 47500, Subang Jaya, Selangor, Malaysia

Email: noorhayati.saad@taylors.edu.my

\section{Patricia Pawa Pitil}

Faculty of Sports Science and Recreation, Universiti Teknologi MARA, Cawangan Sarawak, 94300, Kota Samarahan, Sarawak, Malaysia

Email: patriciapawa@sarawak.uitm.edu.my

\begin{abstract}
This study evaluates the factorial validity of the 21-item of ARS-Revised, which assesses the aesthetic perception of Sarawak Iban Pua Kumbu among its potential buyers at Kuching Waterfront and visitors of Sarawak textile museum and Tun Jugah Foundation Kuching, Sarawak, Malaysia by using a simple random sampling $(N=400)$. An exploratory factor analysis (principal component analysis, Direct Oblimin rotation) was performed to verify the validity and reliability, indicated a new four-factor structure with the 21-item ARS-Revised with five-point Likert scale from the original six-factor. The four-factor solution explained $69.7 \%$ of the total variance. Factor loading of each item reflecting the dimension of the four factors, namely; Knowledge and information and the relation of one have on Pua Kumbu, Historical art knowledge, the technical skills in the making and the attraction towards Pua $K u m b u$, Ability to process information depending on one's knowledge (cognitive stimulation) and Positive attraction towards Pua Kumbu. The overall Cronbach's alpha was high, $\alpha=.925$, indicating that the items has a high internal consistency. The result obtained has proven that the ARS-Revised had high reliability and factorial validity with a new four factors. This paper highlights the validated and the functional of ARS-Revised with four-factor of 21-item with slight differences in assessing the aesthetic perception of Sarawak Iban Pua Kumbu.
\end{abstract}


Keywords: Aesthetic Perception, Art, Ars-Revised, Exploratory Factor Analysis, Reliability, Textiles, Validity

\section{Introduction}

Aesthetic perception involves the values of the feeling towards any visual arts (Bundgaard et al., 2017) which prompts interest, and formed a complicated relationship between visual stimuli and individual understanding which links to generating opinions, either positive or vice versa (Xenakis \& Arnellos, 2014). Some other studies justified that aesthetic perception is not restricted to visual arts but involves a diversity of trans-disciplines of biology, chemistry, physics, mathematics and psychology (Dewey, 2005; Hatch, 2012). Furthermore, studies have agreed that perceptual properties are perceived as more beautiful than others (Berlyne, 1974; Jacobsen \& Hofel, 2003; Ramachandran \& Hirstein, 1999).

The Sarawak Iban Pua Kumbu in Malaysia is one of the top cultural artifacts from the Iban indigenous tribe, and it is a tangible cultural heritage which is protected sacredly by the Iban community, especially the older generation. It is believed, the evaluation of perceptions is an effort to safeguard the Sarawak cultural heritage so it can be transmitted to future generations thus preserving cultural diversity. The complexity of symbols represented in the design motifs that are applied to the Pua Kumbu contributes to the interest, especially among the young generation in understanding the meaning of these motifs (Magiman et al., 2018). Most of the applied design motifs are created with different levels of difficulties, related to the perceivers' aesthetics perceptions that may influence their decision-making in buying the Pua Kumbu. As in the Pua Kumbu situation, the correct information is required to correct the perception of others outside of the Iban community about the motifs with the hope that it will retain the culture motifs (Magiman et al., 2018).

The "one size doesn't fit all' metaphor was inspired from the "one size fit all" which is initially used in the clothing world, designed to fit people of a wide range of size. As this is to the original version of a metaphor, the acronym definition is best to describe the Art Reception Survey (ARS) (Hager et al., 2012) with original of 6 factors and 28 items in the questionnaire was revised accordingly to fit in many form of art domains such as painting, textile, art writing, abstract art and figurative art. In this study, the revised version of ARS-Revised questionnaire were introduced by Wahed et al (2019) with 21items of five factors which is suitable to be applied in the study of Pua Kumbu.

The ARS-Revised of 21-item (Wahed et al., 2019) was used in this study to measure the participants' aesthetic perception of Sarawak Iban Pua Kumbu. The ARS-Revised was the revised version of the original version of the ARS of 28-item (Hager et al., 2012). The ARS credibility on assessing the aesthetic studies is unquestionable with involved of many other aesthetic domains such as art writing (Quiroga, 2020), painting (Miller \& Hubner, 2019; Pietras \& Czernecka, 2018; Wang, 2018), film (Doicaru, 2016), figurative arts (Pietras \& Czernecka, 2018) and abstract art in a museum (Pirgie, 2016). However, there was no study has been conducted to assess aesthetic perception by using the ARS on textile art, except a study by Wahed et al (2019). Therefore, the ARS was revised to a shortened version from 28-item of six factors to 21-item of five factors. This shorter version was derived after the removal of low itemscale correlation of two items from Positive Attraction and Expertise. One factor of five items, which was the Negative Emotion was excluded after considering its content validity besides the low intraclass correlation. It was strongly disagreed to have negative emotions towards the Pua Kumbu. Therefore, this factor was unnecessary for measuring the aesthetic experience towards the textile. 
To further validate the ARS-Revised in assessing the aesthetic experience on Pua Kumbu, the factor analysis was performed. Factor analysis is a technique for arranging, defining, and reducing large items from the questionnaire to other constructs under one dependent variable in a study sample (Chua, 2009). One of the factor analysis technique, the Exploratory factor analysis (EFA) was generated. The EFA tries to uncover complex patterns by exploring the dataset and testing predictions (Child, 2006). In this study, the items of ARS-Revised was explored to validate the inventory. The oblique rotation, Direct Oblimin was performed for a better interpretation of the factors retain in the EFA. A rotation method minimized the number of variables that have high loadings on each factor (Yong \& Pearce, 2013).

Thus, this study aimed to evaluate the 21-item ARS-Revised factorial structure, construct validity and reliability analysis in assessing the aesthetic perception of Sarawak Iban Pua Kumbu among its potential buyers and perceivers.

\section{Methods}

\section{Participants}

The sample consisted of 400 participants who were potential buyers of Pua Kumbu at the sampling frame selected; Kuching Waterfront, and those who visit the Sarawak textile museum and Tun Jugah Foundation, Kuching, Sarawak, Malaysia. The participants were recruited by following a simple random sampling, which means they were selected in a random manner. This sampling technique was chosen as it removes bias from the selection procedure and would result in a representative sample (Proctor, 2005), thus, the homogeneity of the participants was guaranteed. The sample size was $N=400$, which is sufficient when solutions show several high loading marker variables $(>.80)$, as suggested by (Tabachnick \& Fidel, 2001). A sample size of 150 is the minimum number to ensure the analysis of the data is sufficient. Therefore, the sample size of this study is reasonable.

There were 178 (44.5\%) males and 222 (55.5\%) females. They aged between 18 to 21 years old (31.3\%), 26 to 30 years old (19.8\%) and 31 to 35 years old (14\%). Others aged from 36 to 40 years old $(12.3 \%)$ and 41 years old and older (22.8\%). The majority of participants $(78.8 \%)$ were from Sarawak, and some were from Peninsular Malaysia (12\%), Sabah (4.8\%), and foreign (4.5\%). For the education level, most of them had at least A-Level (34.5\%), Diploma (23.8\%) and Bachelor's Degree (11.8\%). Few had a certificate $(8.8 \%)$, Master's Degree (3\%) and PhD (1.3\%). Others were (17\%). Most of the participants had a monthly income from less than Ringgit Malaysia RM1000 to RM3000 (82\%), and few were RM3001 and above (18\%).

\section{Procedure}

The ARS-Revised was administered to visitors who were amongst the potential buyers of Pua Kumbu at Kuching Waterfront and visitors at the Sarawak textile museum and Tun Jugah Foundation Kuching, Sarawak, Malaysia. The data collection was conducted from May 2019 until July 2019.

\section{Measures}

The ARS-Revised (Wahed et al., 2019) is a 21-item tool adapted from the original version of 28-item of ARS (Hager et al., 2012) to assess the aesthetic perception of Pua Kumbu's design motif. It consists of five factors measuring cognitive stimulation, expertise, self-reference, artistic quality and positive attraction. A 5-point Likert scale (1 - strongly disagree, 2 - disagree, 3 - neutral, 4 - strongly agree, 5 - strongly agree) is used. Mean scores were obtained by dividing the summed score to the number of items of each factor. The mean score of each factor was ranging from 1 to 5 . 


\section{Statistical analysis}

The underlying structure of the ARS-Revised was explored using EFA. The EFA was performed after confirming that the data was suitable for factor analysis. Principal components analysis (PCA) was used to extract the factors followed by the Direct Oblimin rotation of factors. This rotational approach was chosen with the assumption of there are correlations between the factors studied. The number of factors to be retained was guided by two decision rules: Kaiser's criterion (eigenvalue above 1), and inspection of the scree plot (Pallant \& Manual, 2010; Yong \& Pearce, 2013). To confirm all factors extracted are reliable, the communality value for each item must be above 0.3 (Tabachnick et al., 2007). Rotation component matrix reporting the factor loadings exceeding 0.3 were included in the analysis. Any item loading value less than 0.3 must be excluded from this analysis.

Construct validity was assessed by using correlation analysis. Pearson correlation coefficients was performed, where $r=.00$ to. 30 is negligible, $>.30$ to.50 is low, $>.50$ to.70 is moderate, $>.70$ to.90 is high and $>.90$ to 1.00 is very high (Cohen et al., 2003). A high correlation indicates a good construct validity.

The reliability of the overall ARS-Revised and five factors was assessed using Cronbach alpha coefficients. Cronbach's alpha ( $\alpha>.80$ good fit and $>.70$ acceptable fit) was used to measure internal reliability (Lance, 2006). The reliability analysis was conducted in each of the factors to ensure all items consistently reflect the construct measured (Hair, 2010).

Descriptive statistics of each factor were presented in mean and standard deviation (M (SD)).

\section{Results}

\section{Exploratory factor analysis}

The sample data was tested for suitability for factor analysis. The Barlett Sphericity Test was significant $\left(\chi^{2}=6193.24, p<0.05\right)$, supporting the factorability of the correlation matrix and the Kaiser-MeyerOlkin (KMO) sampling adequacy measure was .908, supported the matrix factorability (Izquierdo Alfaro et al., 2014). The PCA revealed four eigenvalues exceeding 1, explaining $41.23 \%, 16.17 \%, 7.34 \%$, and $5 \%$ respectively (total $69.7 \%$ ). The inspection of the scree plot also supported a four-factor solution (Figure 1).

Table 1 illustrates the factor loading of the rotation component matrix by using Direct Oblimin rotation. The component matrix details the factor loading onto factors $1,2,3$ and 4 before the rotation. Following the PCA with Direct Oblimin rotation, the items loaded to different factors. Inspection of the pattern matrix showed are relatively clear four-factor solution in contrast with Wahed et al., (2019) where there were five-factor. For Factor 1, artistic quality items; AQ1, AQ2, and $A Q 3$, positive attraction items; P1 and P2 and one item of expertise, E1 were loaded. Thus, this factor represents historical art knowledge on Pua Kumbu, the technical skills in the making, and the attraction towards it. Factor 2 related to items from expertise (E2, E3 and E4) and self-reference (SR1, SR2 and SR3). These expertise and self-reference items loaded strongly to factor 2 . Therefore, this factor represents knowledge and information one has when Pua Kumbu linked to him or her. 


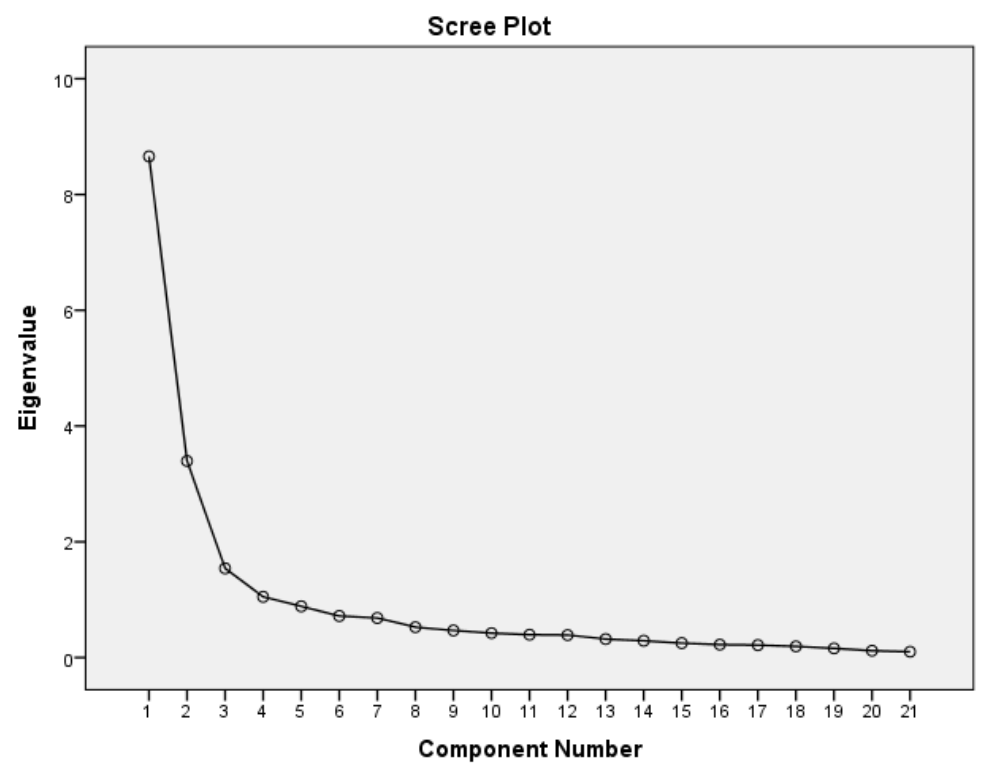

Figure 1: The scree plot for ARS-Revised 21-item

Factor 3 relates to all items in cognitive stimulation, which means this factor represents the ability to process information depending on one's knowledge. Factor 4 relates to all items in positive attraction (P1, P2, P3 and P4) and one item of artistic quality, AQ4. P1 and P2 cross-load to factor 3 and factor 4 with strong loading; .351 and .408 respectively. However, the loadings were higher in factor 4. Therefore, factor 4 represents a positive attraction to Pua Kumbu. Analysis of the rotation component matrix indicated a strong loading of items into factors, including those items which cross-loaded to another factor.

Based on the rotated component matrix results, Factor 1 is artistic quality in terms of technical skill with some knowledge on the historical art and feelings of admiring the beauty and look of the subject matter, Factor 2 relates to skill and knowledge with self-reference, Factor 3 maintain cognitive stimulation, and Factor 4 is a positive attraction and fascination on the creating of Pua Kumbu.

Table 2 shows the new four-factor namely; Knowledge and information and the relation of one have on Pua Kumbu, Historical art knowledge, the technical skills in the making and the attraction towards Pua Kumbu, Ability to process information depending on one's knowledge (cognitive stimulation) and Positive attraction towards Pua Kumbu.

Table 3 shows that the four factors of ARS-Revised revealed a substantial correlation between them. Factor 1 was positively correlated with Factor $2(r=.332)$ and Factor $4(r=.423)$ with low level, while moderate with Factor $3(r=.504)$. Factor 4 was positive moderate correlated with Factor $2(r=.646)$ and Factor $3(r=.586)$. A moderate construct validity was revealed from these correlations results. 


\begin{tabular}{|c|c|c|c|c|c|c|c|c|c|}
\hline \multirow[b]{2}{*}{ Items } & \multicolumn{2}{|c|}{1} & \multicolumn{2}{|c|}{2} & \multicolumn{2}{|c|}{3} & \multicolumn{2}{|c|}{4} & \multirow[b]{2}{*}{ Comm. } \\
\hline & $\mathbf{P}$ & $S$ & $\mathbf{P}$ & $S$ & $\mathbf{P}$ & $S$ & $\mathbf{P}$ & $S$ & \\
\hline CS1 & -.100 & .242 & -.126 & -.414 & -.838 & -.840 & .013 & -.292 & .728 \\
\hline CS2 & .058 & .378 & .109 & -.203 & -.777 & -.791 & -.079 & -.389 & .645 \\
\hline CS3 & -.072 & .255 & -.139 & -.427 & -.851 & -.850 & .062 & -.264 & .748 \\
\hline CS4 & .189 & .473 & -.067 & -.334 & -.583 & -.718 & -.094 & -.425 & .571 \\
\hline CS5 & .160 & .447 & .020 & -.257 & -.619 & -.715 & -.105 & -.419 & .553 \\
\hline E1 & .697 & .658 & -.304 & -.381 & .038 & -.280 & .167 & -.209 & .529 \\
\hline E2 & -.002 & .163 & -.735 & -.805 & -.273 & -.484 & .153 & -.099 & .708 \\
\hline E3 & -.003 & .204 & -.812 & -.873 & -.174 & -.468 & .011 & -.217 & .788 \\
\hline E4 & -.038 & .151 & -.823 & -.854 & -.098 & -.390 & -.009 & -.192 & .736 \\
\hline SR1 & .058 & .273 & -.870 & -.896 & .046 & -.362 & -.164 & -.346 & .835 \\
\hline SR2 & .038 & .252 & -.850 & -.874 & .045 & -.349 & -.169 & -.338 & .793 \\
\hline SR3 & .129 & .322 & -.816 & -.845 & .067 & -.345 & -.155 & -.352 & .762 \\
\hline SR4 & .771 & .794 & -.044 & -.211 & -.115 & -.406 & .062 & -.357 & .647 \\
\hline AQ1 & .832 & .872 & .119 & -.072 & -.085 & -.388 & -.059 & -.463 & .777 \\
\hline AQ2 & .838 & .892 & .058 & -.122 & -.014 & -.367 & -.123 & -.514 & .809 \\
\hline AQ3 & .732 & .837 & -.014 & -.178 & .044 & -.344 & -.254 & -.585 & .748 \\
\hline AQ4 & .035 & .365 & -.139 & -.265 & .040 & -.290 & -.687 & -.707 & .517 \\
\hline P1 & .351 & .623 & .150 & -.085 & -.227 & -.482 & -.445 & -.670 & .614 \\
\hline P2 & .408 & .667 & .232 & -.002 & -.171 & -.438 & -.494 & -.708 & .697 \\
\hline P3 & -.039 & .387 & -.283 & -.456 & -.109 & -.474 & -.706 & -.768 & .720 \\
\hline P4 & -.004 & .426 & -.089 & -.291 & -.144 & -.471 & -.756 & -.828 & .719 \\
\hline
\end{tabular}

$\mathrm{P}=$ Pattern, $\mathrm{S}=$ Structure, Comm. = Communality

Table 1: Pattern and structure matrix for PCA with Oblimin Rotation of four factor of ARS-Revised items

\begin{tabular}{|c|c|c|c|c|}
\hline & F1 & F2 & F3 & F4 \\
\hline F1 & 1 & & & \\
\hline F2 & $.332 *$ & 1 & & \\
\hline F3 & $.504^{*}$ & $.494 *$ & 1 & \\
\hline F4 & $.423^{*}$ & $.646^{*}$ & $.586^{*}$ & 1 \\
\hline
\end{tabular}

\section{Reliability}

The reliability analysis by Cronbach's alpha was reported a high internal consistency, $\alpha=.817-.935$, which was higher than the five factors ARS-Revised. Overall internal consistency was high, $\alpha=.925$ (Table 3).

Descriptive statistics

Table 4 illustrates the descriptive statistics of the four factors of ARS-Revised. The highest mean score was Factor 14.42 (0.73), followed by Factor 24.19 (0.74), Factor 34.06 (0.75) and Factor 43.01 (1.19). 


\begin{tabular}{lccccc}
\hline Five Factor & $\boldsymbol{A}$ & No of item & Four factors & $\boldsymbol{\alpha}$ & No of item \\
\hline SR & .854 & 5 & F1 & .935 & 6 \\
Exp & .835 & 4 & F2 & .860 & 5 \\
CS & .855 & 5 & F3 & .855 & 5 \\
AQ & .809 & 4 & F4 & .817 & 5 \\
PA & .824 & 4 & & & \\
\hline Overall & .925 & 21 & & & \\
\hline
\end{tabular}

$\mathrm{CS}=$ Cognitive stimulation, $\operatorname{Exp}=$ Expertise, $S R=$ Self-reference, $A Q=$ Artistic quality, $\mathrm{PA}=$ Positive attraction

Table 3: Cronbach alpha for five factors and four factors of ARS-Revised

\begin{tabular}{lc}
\hline Factor & M (SD) \\
\hline Factor 1: Historical art knowledge, the technical skills in the making and the & 4.42 (0.73) \\
attraction towards Pua Kumbu & \\
1. I can relate this Pua Kumbu to its historical art context & \\
2. This Pua Kumbu makes me think about my own life history & \\
3. The composition of the Pua Kumbu is of high quality & \\
4. This Pua Kumbu is very innovative & \\
5. This Pua Kumbu features a high level of creativity & \\
Factor 2: Knowledge and information and relation of one has on Pua Kumbu & 3.01 (1.19) \\
1. I know this Pua Kumbu \\
2. I have an idea on what the weaver is trying to convey in this Pua Kumbu \\
3. I can relate this Pua Kumbu to a particular weaver \\
4. This Pua Kumbu mirrors my own personal emotional state \\
5. I can associate this Pua Kumbu with my own personal biography \\
6. This Pua Kumbu makes me think about my own life \\
Factor 3: CS -Ability to process information depending on one's knowledge \\
1. It is exciting to think about Pua Kumbu \\
2. I would like to learn more about the background of this cloth \\
3. It is fun to deal with this Pua Kumbu \\
4. This Pua Kumbu is thought-provoking \\
5. This Pua Kumbu makes me curious \\
Factor 4: PA-Positive attraction towards Pua Kumbu \\
1. The weaver's manner in creating Pua Kumbu is fascinating \\
2. This Pua Kumbu is beautiful \\
3. This Pua Kumbu is pleasant to look \\
4.This Pua Kumbu thrills me \\
5. I feel inspired by this Pua Kumbu
\end{tabular}

Table 4: The Four-Factor of the ARS-Revised 


\section{Discussion}

As detailed in the original author of the ARS (Hager et al., 2012), the instrument would be a valuable and versatile tool for future studies in assessing aesthetics in the different subject matters. The original purpose of this instrument was to evaluate aesthetic perception on paintings, and it discovered different six dimensions of aesthetic experience; cognitive stimulation, negative emotion, expertise, self-reference, artistic quality and positive attraction. This study uses the ARS-Revised of five-factor of 21-item which was validated previously in assessing the aesthetic perception of Pua Kumbu design motifs (Wahed et al., 2019). Some items were omitted due to low internal consistency and negative emotion was removed after considering its irrelevant, based on content validity. Therefore, altogether a pool of 21 items entered the analysis.

The EFA was performed to assess validity has observed a significant finding. The original 21-item of the ARS-Revised remains, however, the number of factors was composed.

The PCA with Direct Oblimin rotation pointed a four-factor solution, explaining almost $70 \%$ of the data's variance. The factor that explained most of the variance was Factor 1 with five items, describes the historical art knowledge and information on the originality and technical skills in the making of Pua Kumbu. One of the items expresses the relation of one's think about his or her life history. Factor 2 loaded with 6 items describes knowledge and information and the relation of one has on Pua Kumbu. Individuals who scored high in this factor know and have an idea of what the weaver tries to convey in the Pua Kumbu and could relate the Pua Kumbu to a particular weaver. They also tend to associate Pua Kumbu information to their personal emotional state, biography and memories. Factor 3 was cognitive stimulation which was loaded with five items. This factor remains the five items as in ARS-Revised. It describes the perceiver's intellectual devotion to Pua Kumbu. Individuals who score high on this factor are intellectually intrigued by the Pua Kumbu. They enjoy thinking about the Pua Kumbu and curious to learn more about the weaver and background. The fourth factor which was loaded with five items, pronounces the positive attraction towards Pua Kumbu and fascinated in the manner of the weaver in creating this masterpiece. It consists of items referring to beauty, pleasantness, and emotional engagement, such as being thrilled and inspired.

The reliability analysis of the ARS-Revised of five factors revealed a high internal consistency. However, with the new four factors, the internal consistency increased. This indicated that the items in each factor are more related as a set of groups. The overall internal consistency was very high, $\alpha$ $=.925$. The four-factor obtained in this study contributes to the growing body of studies investigating the factor structure of the ARS-Revised. The original work by Hager et al., (2012) to Wahed et al., (2019) to the present paper proof the study using this instrument is promising to explore the aesthetic perception in artworks.

The correlations between factors explain a construct validity of the new four-factor ARS-Revised. The relationships were positive and moderately strong revealed that each factor is interrelated in assessing aesthetic perception. On the other hand, the descriptive results revealed the highest mean score amongst the four factors was Factor 2. This factor describes the historical art knowledge and information on the originality and technical skills in the making of Pua Kumbu. One of the items 
expresses the relation of one's think about his or her life history. The results imply that the perceivers were likely to have artistic value on Pua Kumbu in terms of its quality, innovation and creativity. Historical relation existed between their life history and the historical art knowledge through this Pua Kumbu. This makes sense due to the Pua Kumbu itself is strongly related to a historical event, involve Iban tribe and their culture back in ancient days. The making of Pua Kumbu is well-known by weavers who are talented and chosen ones, and its design motifs are always the main attraction in admiring the textile.

The least mean score was Factor 1, where it describes knowledge and information and the relation of one has on Pua Kumbu. Given the circumstances that the perceivers were the potential buyers of Pua Kumbu, they might have lacked information and somewhat has less relation to this art piece. This could be explained by the lack of knowledge among the participants, especially on the making of Pua Kumbu, in terms of its weaving, technique, and history. This is supported by a study on painting artwork (Pietras \& Czernecka, 2018; Saxena \& Jain, 2014), where those with prior knowledge of artwork would influence their aesthetic perception.

\section{Conclusion}

As the outcome from EFA with Direct Oblimin rotation, four factors of the ARS-Revised were suggested. Internal consistency was high and construct validity presented a valid measure. In sum, the study managed to validate the functional of ARS-Revised with four-factor of 21-item with slight differences in assessing the aesthetic perception of Sarawak Iban Pua Kumbu.

\section{References}

Berlyne, D. E. (1974). Studies in the new experimental aesthetics: Steps toward an objective psychology of aesthetic appreciation. Hemisphere.

Bundgaard, P. F., Heath, J., \& Ostergaard, S. (2017). Aesthetic perception, attention, and nongenericity: How artists exploit the automatisms of perception to construct meaning in vision. Cognitive Semiotics, 10(2), 91-120.

Child, D. (2006). The essentials of factor analysis. A\&C Black.

Chua, Y. P. (2009). Statistik penyelidikan lanjutan I: Ujian univariat dan multivariat. Buku 4. McGrawHill (Malaysia).

Cohen, J., Cohen, P., West, S. G., \& Aiken, I. S. (2003). Applied Multiple Regression/Correlation Analysis for the Behavioral Sciences. NJ:Eribaum.

Dewey, J. (2005). Art as experience. Penguin.

Doicaru, M. M. (2016). Gripped by movies: From story-world to artifact absorption. Unpublished doctoral dissertation). University of Amsterdam.

Hager, M., Hagemann, D., Danner, D., \& Schankin, A. (2012). Assessing aesthetic appreciation of visual artworks-The construction of the Art Reception Survey (ARS). Psychology of Aesthetics, Creativity, and the Arts, 6(4), 320.

Hair, J. F., Black, W.C., Balin, B.J., Anderson, R.E (2010). Multivariate Data Analysis. Maxwell Macmillan International Editions.

Alfaro, I., Diaz, O. J., \& Abad García, F. J. (2014). Exploratory factor analysis in validation studies: Uses and recommendations. Psicothema. 
Jacobsen, T., \& Hofel, L. (2003). Descriptive and evaluative judgment processes: Behavioral and electrophysiological indices of processing symmetry and aesthetics. Cognitive, Affective, \& Behavioral Neuroscience, 3(4), 289-299.

Jo Hatch, M. (2012). The pragmatics of branding: an application of Dewey's theory of aesthetic expression. European Journal of Marketing, 46(7/8), 885-899. https://doi.org/10.1108/03090561211230043

Magiman, M. M., Chelum, A., Durin, A., Nie, C. L. K., \& Mohd Yusoff, A. N. (2018). The Iban's Belief towards the Meaning of Pua Kumbu's Motif. Scholars Journal of Arts, Humanities and Social Sciences, 6(8).

Miller, C. A., \& Hübner, R. (2019). Two routes to aesthetic preference, one route to aesthetic inference. Psychology of Aesthetics, Creativity, and the Arts.

Pallant, J., \& Manual, S. S. (2010). A step by step guide to data analysis using SPSS. Berkshire UK: McGraw-Hill Education.

Pietras, K., \& Czernecka, K. (2018). Art training and personality traits as predictors of aesthetic experience of different art styles among Polish students. Polish Psychological Bulletin, 49(4), 466-474.

Pirgie, L. S. (2016). Lost in contemplation of original artworks uniwien].

Proctor, T. (2005). Essentials of marketing research. Pearson Education.

Quiroga, M. (2020). Social desirability, need for uniqueness, and the illusion of explanatory depth in perceptions of the fine arts

Ramachandran, V. S., \& Hirstein, W. (1999). The science of art: A neurological theory of aesthetic experience. Journal of consciousness Studies, 6(6-7), 15-51.

Tabachnick, B. G., Fidell, L. S., \& Ullman, J. B. (2007). Using multivariate statistics (Vol. 5). Pearson Boston, MA.

Wahed, W. J. E., Yusoff, S. B. H. M., \& Saad, N. (2019). Reliability and Validity of Questionnaire on Assessing the Aesthetic Perception of Design Motif Applied on Sarawak Pua Kumbu Cloth Using the Art Reception Survey (ARS). Journal of Visual Art and Design, 11(2), 135-145.

Wang, W. (2018). Narcissistic Intolerance: Verbal Hostility and Dismissiveness in Response to Subjective Disagreement.

Xenakis, I., \& Arnellos, A. (2014). Aesthetic perception and its minimal content: a naturalistic perspective. Frontiers in psychology, 5, 1038.

Yong, A. G., \& Pearce, S. (2013). A beginner's guide to factor analysis: Focusing on exploratory factor analysis. Tutorials in quantitative methods for psychology, 9(2), 79-94. 